\title{
The Classical Tilt of Justificatory Liberalism ${ }^{1}$
}

European Journal of Political Theory, forthcoming (2013)

Andrew Lister

Department of Political Studies

Queen's University

andrew.lister@queensu.ca

Jan. 18, 2012 (SSRN Draft)

The Order of Public Reason is Gerald Gaus's important new statement of justificatory liberalism. The idea of public justification is roughly that the exercise of political power must be justifiable to all those over whom it is exercised, where "justifiable to..." X, Y, and Z means acceptable to each of $\mathrm{X}, \mathrm{Y}$, and $\mathrm{Z}$ assuming only some basic form of reasonableness, without $\mathrm{X}, \mathrm{Y}$ or $\mathrm{Z}$ having to give up the conflicting but reasonable religious or philosophical perspectives they espouse. However, the book is much more than a refinement of Gaus's political philosophy. The Order of Public Reason attempts to explain and justify social morality; only in the last third of the book does Gaus attempt to trace the limits that a bona fide social morality places on the legitimate exercise of political power. The book is highly synthetic, drawing on work in game theory, evolutionary psychology, and moral philosophy, as well as political theory. As it is also long, there is a danger that readers will miss the forest for the trees. The initial purpose of this essay is therefore to explain how the overall argument is meant to hang together. Having done that I will identify in a very preliminary way four points at which the argument might be challenged, particularly as it relates to justificatory liberalism's "classical tilt."2

The Order of Public Reason is animated by two fundamental problems. The first is the problem of authority in morality. This problem arises in relation to "social morality," all those moral rules that structure social interaction by requiring or prohibiting actions and grounding the demands we make of each other (2-3). On Gaus's view, at the heart of social morality lie claims to personal authority (8), meaning authority of one person over another, rather than the intellectual or epistemic authority that morality itself has over me. "Morality makes my actions your business, and so gives you standing to tell me what I must do" (9). Morality involves passing judgment, allotting blame, waxing indignant, making others feel guilty, and so on. By what right do we inflict this all on each other? (xvi, 5) It may be admirable to act on one's own view of what morality requires, but imposing this morality on others may seem distasteful or unhealthy, on Nietzschean grounds $(5,315)$, and it stands in tension with the commitment to respect others as free and equal persons who must take responsibility for acting on their own best understanding of what morality requires. As Locke argued, the natural liberty of man is to be free from dependence on the arbitrary will of any other man, but to have only the law of nature as his guide. A free moral person is thus "one who acts according to her own reasoning about the demands of morality," not the judgments of others about what morality demands (14-15). In the face of reasonable moral disagreement, the claims to authority we make on each other in everyday moral life may simply be authoritarian.

The second problem The Order of Public Reason addresses is how to reconcile Humean / evolutionary and Kantian / justificatory accounts of moral rules. On the Humean view, moral 
rules exist to serve a function, which is to make peaceful, productive social life possible. On the Kantian view, moral rules are justified independent of the beneficial contingent effects that our following them may have. This difference in perspective corresponds to the distinction between first and third person points of view. As a participant in social morality, I take moral rules to be binding and authoritative apart from the effects of my following the rules. As an observer, I recognize that morality evolved via selection pressures and cultural learning because it helped solve the problem of social cooperation, in a context in which groups failing to solve this problem quickly ceased to exist. The conflict between the first and third-person perspectives on morality would be easily resolved if it could be shown that social morality serves a useful function and is therefore rationally justified, as a means to this end. However, in Gaus's view, this "instrumentalist" approach to social order is a failure. Gaus defends this claim by reviewing the various attempts to solve the prisoner's dilemma, concluding that "the problem of social cooperation cannot be resolved by individual instrumental rationality:... [it] requires the firm social expectations provided by social rules issuing strong requirements" (i.e. requirements to act in certain ways even when doing so does not best promote one's goals; 99, 135-6).

Fortunately, there is good reason to think that evolutionary processes have generated a disposition to follow rules conditional on the expectation that others are following rules too, a disposition psychologists and economists refer to as "strong reciprocity." In competitive situations, a group of Unconditional Rule-Followers will outperform a group of purely instrumental Defectors, but any Defector who enters the group of Unconditional Rule-Followers will outperform his fellows. Such invaders can be kept at bay if there are enough Rule-Following Punishers in the group, who altruistically provide the public good of punishing rule-violators. Rule-Following Punishers have a fitness disadvantage relative to Easy-Going Rule-Followers (who follow rules but don't punish violations), but if defectors aren't common and the cost of punishing is not too high, a cooperative outcome may be stable. Gaus surveys a range of experimental data showing that human beings are in fact Rule-Following Punishers, by and large (118-122).

While plausible, this account of human psychology does not resolve the puzzle about the rationality of following moral rules, as distinct from the usefulness of general rule-following. I may acknowledge that I have an innate disposition towards conditional rule-following, but question whether I have sufficient reason to acquiesce in it. The main element of Gaus's answer comes in the final chapter of Part 1, which shows that rule-following is intimately related to our emotional lives and the relationships we have with other people. Even if the instrumental justification of morality went through, it would not support attributions of blame and demands for conformity; at most it would support attributions of imprudence or irrationality (185). Social morality involves people resenting the wrongs they have suffered, being indignant at the wrongs other people suffer, forgiving people who apologize and make amends, and so on. Our expression of these feelings does help regulate behaviour in desirable ways, but Gaus follows P. F. Strawson in thinking that our "reactive attitudes" are not just tools we deploy in a calculating way. We think it appropriate to have such attitudes, and to care about the attitudes of others, and this makes sense because these attitudes are constitutive of personal relationships. As Rawls argued, love and friendship imply a liability to have moral feelings: joy if a friend does well, grief if they suffer, indignation if they are treated badly, and so on. ${ }^{3}$ We could not give up our susceptibility to such feelings without giving up the concern we have for our relationships with oth- 
er persons (c.f. 192).

Strawson also showed that these "reactive attitudes" only make sense if we believe that the persons who are their object have a certain degree of autonomy. The resentment one initially feels at an injury will be diminished if one finds out that the person responsible was at the time deranged by grief at the loss of his child, or under post-hypnotic suggestion. Gaus argues that the same holds with respect to small children and psychopaths, who may know the rules but who have not internalized them. There is no sense in addressing an authoritative prescription to someone who hasn't grasped the idea of morality as an internalized authority, someone who can only interpret such prescription as implicit threat (209). In what is perhaps the central section of the book, Gaus argues that the presuppostions of our reactive attitudes go beyond this minimal capacity for moral agency. Someone might be capable of caring for moral rules, but have a systematically perverted set of beliefs, as a result of indoctrination à la 1984. Or, they might wrongly but still reasonably have fundamentally different beliefs. If you wrong me in some way, but I come to realize that you genuinely and reasonably don't agree with what I take to be the applicable moral rule, my resentment at your rule-violation must be undermined, Gaus claims (220-21). We might express this point by saying that your rule-violation doesn't express disrespect for me and my standing as a moral person, because you were acting according to your own conscientious view of what morality and proper respect for me as a person require. Gaus concludes that we can address moral prescriptions to others only if they are moral agents and have sufficient reason to endorse the rules in question (222).

One might think that everyone does have sufficient reason to follow rules that are valid or correct, just in virtue of their being valid or correct. Yet whatever we may think reasons are, whatever reasons we may think there are, to have a reason must be to have access to a reason given one's current epistemic situation (235). While people can wrongly think that they have a reason (e.g. neurotic fear of horses), and fail to recognize reasons they do have (e.g. Mill's example of a man about to cross a bridge that he doesn't know is unsafe), Aristotle did not have a reason to believe in contemporary particle physics. People only have reasons to do or believe $\mathrm{X}$ if a respectable amount of good quality deliberation could lead them to conclude that they should do / believe X (250). Social morality can only be truly consistent, it turns out, if its rules are ones all normal moral agents have sufficient reason to endorse, despite their inevitable, often deep, but still reasonable disagreements. When social morality meets this public justifiability constraint, authority and autonomy are reconciled.

Thus we arrive at Gaus's "Basic Principle of Public Justification:"

"A moral imperative " $\varphi$ !" in context $\mathrm{C}$, based on rule $\mathrm{L}$, is an authoritative requirement of social morality only if each normal moral agent has sufficient reasons to (a) internalize rule $\mathrm{L}$, (b) hold that $\mathrm{L}$ requires $\Phi$-type acts in circumstances $\mathrm{C}$ and (c) moral agents generally conform to L" (263).

The main element of the BPPJ is (a), which is a restriction on what can count as a bona fide rule of social morality, to wit, that every normal moral agent have sufficient reason to endorse the rule in question (L), despite the evaluative diversity that characterizes such agents. (b) is the analogous constraint on the derivation of imperatives from rules, while (c) is a reciprocity requirement corresponding to the conditional nature of rule-following discussed in Chapter III. 
The crucial point is that the BPPJ "is not an ideal imposed upon morality by a philosophical commitment to the idea that moral agents are free and equal but is itself grounded in our reflective understanding of a bona fide social morality - one in which the moral emotions are well grounded and for which it is appropriate to feel guilt for violations" (263). At the heart of the book, therefore, is a kind of transcendental argument. Starting from very basic aspects of our moral practices, such as feeling resentment and indignation and issuing authoritative prescriptions to other people, and reflecting on the situations in which we recognize that such attitudes and imperatives do not make sense, we come to see that these practices presuppose a conception of moral autonomy and an associated requirement of public justifiability for putative moral rules.

How do we know what moral requirements all normal moral agents have reason to internalize? To answer this question, Gaus formulates a "deliberative model," in which partly idealized counterparts of normal moral agents deliberate in a specific setting. These "Members of the Public" are willing and able to reason with each other (they do not engage in bargaining or strategic behaviour; 276), and they accept certain basic moral ideas implicit in the goal of discovering a publicly justified morality, such as the recognition of others as free and equal persons (279), but they reason from diverse evaluative standpoints, restricted only by the requirement that these standpoints be mutually intelligible as moral views. Thus Gaus rejects the Rawlsian requirement that Members of the Public deliberate only on the basis of shared reasons (283-92). The task of Members of the Public is to deliberate about particular social rules, and such deliberation must be comparative. To know whether I have sufficient reason to endorse a rule L, I must know what the alternatives to L are (268-9, 311-12). Some proposed rules might be absolutely unacceptable, in the sense that I rank the rule in question below the proposal of not having any common rule at all, on the matter at hand, which would leave everyone free to act on their own conscientious convictions, without any authority to demand particular forms of conduct from others. Because moral rules must be supported by the reasons of all normal moral agents, the absence of a rule has the status of a default. Claims to authority must satisfy a partly idealized unanimity requirement, otherwise we default to "moral no-authority - blameless liberty" (321). The set of proposals one Member ranks as preferable to no-rule is her "individual eligible set;" the set of proposals all Members of the Public prefer to no-rule is the "socially eligible set." Invoking Pareto, we can drop proposals that we all agree are worse than some other proposal in the set, arriving at the "optimal eligible set" or OES (323). Because the Members of the Public are idealized, the OES will often not be empty; because they are only partly idealized, the OES will rarely be a singleton. In other words, Members of the Public will typically agree that a variety of rules are preferable to no-rule, but disagree about which rule is best (391).

It would be natural at this point to say that we ought to choose from the OES by some publicly justifiable decision-procedure. However, we are unlikely to agree about which decision-procedure is best. Gaus resolves this quandary by denying that the procedure of choice needs to be uniquely publicly justified in order for the rule it selects from the OES to be justified. Suppose that history and cultural evolution have led us to coordinate on a particular member of the OES. Some may think the rule in question morally optimal, but everyone else faces the following situation. I can either act according to L, which is not ideal but which is better than norule and which everyone else is currently following, or I can act according to my preferred rule $\mathrm{M}$, which I think is ideal but which no one else is currently following. Gaus argues that in this 
situation I can have sufficient reason to act on L, solely based on my own evaluative standards, particularly if the number of persons with whom I am interacting is large. Other things equal it would be better for me to act on $\mathrm{M}$ than on $\mathrm{L}$, of course, but others things are not equal because only L provides the basis for me to make moral demands of others in a way that is consistent with respecting their freedom and equality (398-99).

Among Members of the Public, lack of a publicly justifiable morality would mean that individuals refuse to claim authority over others but act according to their own more or less reasonable moral conscience. Among real human beings, in contrast, the lack of effective social rules might mean that life would be nasty, brutish and short, rather than simply unpredictable, inconvenient, or chaotic, because some people are not at all reasonable. For this reason, it might be preferable to have some social rules, even if very immoral, as opposed to not having any at all. Such rules would be merely social conventions lacking in moral authority because outside the OES (436). Dislodging this social equilibrium on bad rules may require a political authority which can announce and enforce new rules, Gaus concedes (449). However, political authority can also move society in the opposite direction (457). Hence in Gaus's view we ought to be very sceptical of the political process, and disinclined to make changes if we are already at a bona fide moral equilibrium (460).

What then are the limits of the state's right to enact and enforce laws governing people's conduct? The answer depends on the choice Gaus makes about the unit of public justification. Do we require that each individual moral rule meet the idealized unanimity test (otherwise we default to not having a rule in the domain in question), or do we require only that whole systems of moral rules meet the test (otherwise we default to no-system)? Gaus's initial answer is that we must focus on specific moral rules that directly guide individual conduct, because holistic assessment of systems of rules is cognitively too demanding, and because social cooperation depends on coordinating on specific rules, not abstract principles (272-3). However, Gaus also admits that the justification of any one rule may depend upon what other rules are in place, calling this an instance of "moral structure." The idea is that some rules are more basic than others and so come first in the "order of justification" (275). The more basic rules, such as free speech, are closer to being principles, in the sense that they are less determinate and less subject to convergence in judgment about their proper application. Abstract principles are "not the ultimate aim of public justification," but if Members of the Public can agree on some abstract principles "they would at least have narrowed their problem to the justification of rules that are adequate interpretations of the already justified principles" (337).

To ground such abstract principles, Gaus argues that despite the diversity of their evaluative standards Members of the Public share a conception of themselves as agents, and that this "perspective of agency" secures certain basic rights. The perspective of agency does not include a commitment to personal autonomy, whereby one would try to subject all of one's goals to critical scrutiny (338-39). Still, this perspective justifies a presumption in favour of liberty, that it is wrong to exercise one's liberty so as to threaten the agency of others without justification (341). Coercion - which at this stage just means threats to one's natural person - is one clear instance of interference with agency. Constraint of discourse aimed at inducing agents to believe one thing rather than another is another clear instance (353). Thus the right not to harmed and freedom of thought are abstract rights that are basic in the order of justification. These rights are justified 
pro tanto, from the perspective of agency, but also all things considered, given the various full sets of reasons Members of the Public accept, for all conceive of themselves as free and equal moral persons, and thus are only willing to make claims of moral authority that are endorsed by the reasons of others; the rights of agency are "stable under full justification," to use the Rawlsian terminology (360). In contrast, "strong" duties of assistance, while justifiable pro tanto based on the shared perspective of agency, are not stable under full justification because some people reasonably accept principles of desert (362-3).

To justify the right to private property, Gaus appeals to the "jurisdictional" function of rights. If evaluative diversity makes it hard to find a uniform way to regulate the "moral space," we can "partition" it, allowing each person's values to be sovereign over a portion of this space. Following Hayek, Gaus argues that private property is a way of coping with disagreement. The rules that prevail in a Catholic church are not the same as those that prevail in a university seminar room or in a strip club (374-5). Property rights must include the right to own the means of production as well as personal property. For many people, work is not just a means to an end but an intrinsic part of their conception of the good life. Entrepreneurship ("start-ups, innovation, risktaking, organizing groups and solving problems") is a form of human flourishing, according to some reasonable views (379). If workers prefer to share in these values they can form cooperatives, but if hierarchical firms are more efficient and can offer higher wages, workers must be free to choose higher income at some cost in terms of independence and self-development (380). Gaus later provides a separate argument for private property rights, which is that as an empirical matter, "extensive private ownership - including capital goods and finance - is for all practical purposes a requisite for a social and political order that protects civil liberties" (513). Socialist systems would therefore still be outside the socially eligible set even if one rejected Gaus's argument for the abstract right of private property (512). Gaus rejects the Rawlsian claim that economic inequality tends to undermine political equality on the basis of the fact that there is little correlation between Freedom House's measure of OECD countries' protection of political rights and the degree of income or wealth inequality in these countries (517-520).

With the overall argument now in view, I want to raise one question about its starting point, and three questions about the way Gaus frames the principle of public justification and how this framing influences the conclusions he reaches.

Early on, Gaus addresses the "obvious objection" (9) that in making a moral demand I am not claiming that you must submit to $m y$ authority, but to the authority of morality. Gaus's response to this, the authority-of-morality objection, is that moral demands in face of disagreement involve claims to deference in judgment. Suppose Alf and Betty disagree about whether L requires $\theta$. Alf says “you ought to $\theta$ because L." Betty says "no, L doesn't require $\theta$." At this point Alf can continue to argue that $\mathrm{L}$ requires $\theta$, or he can threaten to impose some sanction if Betty doesn't $\theta$, but Gaus thinks that moral demands involve a third response, which is roughly this, on the part of Alf: "Despite the fact that you deny that $\mathrm{L}$ requires $\theta$, you ought to $\theta$, because you ought to defer to my judgment about what L requires" (c.f. 12). Clearly there are particular situations in which I might claim that you should defer to my judgment because I have more experience in the area in question, but why must social morality generally involve claims to deference in judgment? If after deliberation we conclude that we reasonably disagree about what the relevant moral rule is or what action it requires, I can stop criticizing and blaming you until such time 
as the matter is settled politically. In this case, moral "demands" would simply be claims about what morality requires, without any suggestion that if you disagree you should nonetheless follow my judgment. The claim that you should do as I say even though you disagree about what morality requires is characteristic of political authority, we might think, not morality as such; we have a right that others defer to the collectivity's judgment about what morality requires only when this judgment has been made via an appropriate procedure and codified as law. In short, we can think of moral demands as involving either rational argument about what is right or appeals to political authority without any claim to deference in moral judgment.

The second issue I want to raise concerns the way the argument moves from the Basic Principle of Public Justification to specific conclusions about what rights we have. Gaus's general approach is to argue that various abstract rights are justified pro tanto based on our shared perspective of agency, but that only some of these rights are stable under "full justification," i.e. only some of these rights are justified all things considered on the basis of each Member of the Public's full set of reasons. From the shared perspective of agency we should accept "some fairly strong welfare rights" (358-9), he admits. Yet once we bring in the full diversity of reasonable evaluative standards, we have to recognize that differences of opinion about desert, risk, responsibility, and so on lead some reasonable persons with reasonable points of view to reject the strong right of assistance. Now, Gaus recognizes that the rights justified on the grounds of agency and endorsed under full justification are abstract (350). Thus in the section on the limits on the argument from abstraction (17.6), Gaus imagines a debate between three Members of the Public who agree on the abstract right to freedom of speech, but disagree about how exactly it should be specified, and so disagree about how far the right should protect explicit sexual content, for example. The three Members of the Public see reason to select one of the three specifications of the right, but do not agree which interpretation is best (369-70). Thus, Gaus treats competing specifications of the abstract principle of free speech as being on a par, and concludes that our task is to find a way of selecting from the set of eligible interpretations. In contrast, in the right of assistance case, Gaus seems to classify competing specifications as weaker or stronger, recognizes reasonable disagreement about which is optimal, and concludes that we must default to the weaker specification. Why the difference between the two cases?

One answer would be to claim that it is reasonable to reject the strong right of assistance as against the alternative of not having any right of assistance at all, whereas none of the three specifications of the right of free speech is reasonably rejectable as against not having any such right. This may be Gaus's view, but to my mind all he shows is that it is reasonable to deny that the strong right of assistance is best, not that it is reasonable to prefer no right of assistance at all. There must be some extravagantly strong specification of the right to assistance that is reasonably rejectable as opposed to none at all. So let us weaken the right of assistance until we arrive at the strongest interpretation that is better than no such right at all; this medium-strength right of assistance would then constitute the outer limit of the eligible set. There is some range of interpretations of the abstract right of assistance that under full justification are preferable to none at all, just as there is some range of eligible interpretations of the right of free speech. Within these sets of eligible interpretations, Gaus's theory provides no reason for preferring weaker to stronger interpretations.

A second answer would be for Gaus to offer some criterion for ranking specifications in 
terms of strength, and a principle that in the absence of unanimous agreement on a stronger specification we default to the weaker specification. We might think of this as the incremental application of the unanimous acceptability criterion. For example, we might say that a law will not be legitimate simply because it is unanimously preferred to no-law, on the matter at hand; it would also have to be unanimously preferred to any less coercive laws that are preferable to nolaw. Gaus rejects this continuous application of the unanimity criterion on the grounds that so long as the law chosen is a member of the eligible set, every Member of the Public does have sufficient reason to endorse that law as authoritative based purely on her own evaluative standards, given what everyone else is doing (502). Having a sufficient reason to endorse an existing rule as authoritative is not the same as being justified in enacting that rule, however. Gaus's official rejection of the incremental version of the principle is cast in terms of the reasons for recognizing an existing law as authoritative, but there is a separate question about what form of the principle we should employ when we vote on reforming our laws. Gaus's treatment of the right to assistance suggests that in this case (but not the case of free speech) he may be tacitly relying on an incremental version of the principle.

My third question concerns Gaus's treatment of coercion. The presumption in favour of liberty and against coercion is not just a tie-breaker, in situations where the cases for and against seem evenly matched. Coercion requires public justifiability; "all Members of the Public must have reason to endorse [a law L] as overriding their right not to be coerced" (481; compare to 341). Yet the fact that coercion is bad other things equal doesn't imply that a coercive law is permissible only if it passes the idealized unanimity constraint. Gaus insists that the presumption against coercion is not a goal of minimizing coercion, giving the example of Draconian laws that would minimize overall coercion by executing people for trivial offences. No doubt such a policy would be wrong, but this would be because it would violate specific rights people have against cruel and unusual punishment, not just because someone could reasonably think the law in question worse than no law at all. Gaus's view implies that laws that do not violate basic rights are still not legitimate if they are not unanimously acceptable in the idealized Public, on the grounds that there is a side-constraint against reasonably-rejectable coercion. For all side constraints, the question is why the prohibited act is so bad or bad in such a way that one is not permitted to do it even for the sake of preventing more such acts on the part of others. Side constraints are controversial even for rights against particular forms of mistreatment, such as torture, but they are even harder to accept for such a broad right as the right not to be coerced.

Moreover, if we are really just talking about an "abstract right", the precise contours of which will be the subject of reasonable disagreement $(341,479)$, how has Gaus managed to arrive at such a particular specification? An abstract right not to be coerced would leave unspecified exactly what constitutes coercion, in what context the right applies, and so on. Yet Gaus's right is quite definite and specific, in that it applies to all threats against one's person, all limitations of one's rights, and indeed all state action not directly required by those rights. This is one reasonable interpretation of the right not to be coerced, no doubt, and Gaus is free to argue for it, but it is not required by the apparatus of public justification, at least so long as public justification starts with abstract principles, and then moves to interpretations of these principles.

The fourth question I want to raise concerns the unit of public justification. From one perspective, it seems obvious that classical liberalism should have a classical tilt; no one can 
reasonably reject having a scheme of private property rights, but classical liberals and libertarians can reasonably reject egalitarian redistribution. Yet Gaus recognizes that the justification of property and redistribution cannot be separated in this way, because some Members of the Public cannot rank schemes of private ownership unless they know whether redistributive programs will be in place (521-22). Gaus's criterion of "justificatory dependency" for individuating issues holds, roughly, that issues $\mathrm{X}$ and $\mathrm{Y}$ are independent only if there is no Member of the Public whose ranking of proposals on $\mathrm{X}$ depends on what policy is in place on $\mathrm{Y}$ (495). This criterion introduces a much stronger degree of holism into Gaus's model of public justification than was initially apparent. In this context, greater holism means (i) a non-coercive default that approaches the state of nature, as the level of aggregation increases, and (ii) an ever larger OES, since many different packages of policies, some highly coercive, will be better than not having any common rule in any of these areas of policy.

Regardless, Gaus maintains that justificatory liberalism inclines against egalitarian redistribution, for two reasons. First, because of the empirical argument about protecting civil and political liberties, socialist regimes are ruled out but some nightwatchman regimes are ruled in. The boundaries of the OES are thus not symmetrical about the political centre. This argument does not establish any tilt within the OES, however. The great importance of protecting civil and political liberties still leaves a lot of room for variation in policies regarding taxation, regulation, and, public spending, including even perhaps public ownership of some parts of the economy; the optimal eligible set presumably includes systems of from the Right, Middle, and what we might call the Responsible Left. Justificatory liberalism does not incline us in favour of one of these over the other - it does not push us right or pull us leftward within the OES - because all public justification requires is unanimous (idealized) acceptability compared to no-rule. Gaus's second argument is that high-tax redistributive states will be more coercive, due to rising rates of noncompliance, and due to the fact that at higher rates of taxation a range of market transactions become increasingly costly to engage in, in contrast with non-market transactions (523-4). It is not unreasonable, however, to think that as the degree of redistribution and provision for basic needs decreases, the property system itself becomes more coercive (for those without money, Gerald Cohen would say ${ }^{4}$ ). Different people will assess the costs and benefits of coercion differently; the only issue, for Gaus's model, is what systems are morally preferable to none at all (according to all Members of the Public). The only way Gaus could argue that justificatory liberalism is tilted against redistribution within the set of eligible property systems is to adopt the incremental version of the principle, which he wants to avoid, for fear of the barely-reasonable Libertarian Dictator, whose objections would trump any democratic move towards more coercive members of the socially eligible set (501-2). Gaus's conclusion that justificatory liberalism has a "strong overall inclination" towards classical liberalism therefore seems to me overstated (526).

It is not surprising that people with different political leanings should disagree about the practical implications of the demand for public justifiability. Although my questions have focused on the policy consequences of justificatory liberalism, I would not want to distract attention from the more general philosophical argument of the book. Public reason is a condition of possibility for aspects of ourselves and our social relationships that we can't imagine dispensing with. Both advocates and critics of public reason will have to grapple with this fundamental claim. 


\section{Notes}

1. This essay has benefitted greatly from comments by Blain Neufeld, Tom Porter, Jonathan Quong, and Kevin Vallier.

2. Gerald F. Gaus, The Order of Public Reason: A Theory of Freedom and Morality in a Diverse and Bounded World (Cambridge: Cambridge University Press, 2010), 501, 528, 526. All future references to this work will be made parenthetically in text. The phrase "classical tilt" also serves as the title of a recent essay; Gerald F. Gaus, "Coercion, Ownership, and the Redistributive State: Justificatory Liberalism's Classical Tilt," Social Philosophy and Policy 27 (2010): 233-75.

3. John Rawls, A Theory of Justice (Cambridge, Mass.: Harvard Univeristy Press, 1999), 425-27.

4. G. A. Cohen, "Freedom and Money," in On the Currency of Egalitarian Justice, and Other Essays, ed. Michael Otsuka (Oxford: Oxford University Press, 2011). 